\title{
Economic values for evaluating pasture plant traits
}

\author{
D.F. CHAPMAN ${ }^{1}$, J.R. BRYANT ${ }^{2}$, W.H. McMILLAN ${ }^{2}$ and E.N. KHAEMBAH ${ }^{2}$ \\ DairyNZ, ${ }^{1}$ P.O. Box 160, Lincoln University, Lincoln 7647 and ${ }^{2}$ Private Bag 3221, Hamilton 3240, New Zealand \\ david.chapman@dairynz.co.nz
}

\begin{abstract}
Economic values (EVs) are an estimate of the change in farm system profit per unit of change in a defined plant trait. Cultivars within species such as perennial ryegrass differ in the major production traits of dry matter yield, nutritive value and persistence, but the impact of those differences on farm financial performance is seldom calculated and reported. This paper explains what EVs are, describes how they can be calculated, and discusses some of the associated methodological issues. EVs have been derived for seasonal dry matter yield in New Zealand dairy systems. Extra feed produced in late spring has consistently low economic value, while extra feed produced in early spring has consistently high value. There have been no systematic investigations into the EVs of nutritive value and persistence in New Zealand pastures; this is a clear opportunity for future research. The lack of data on cultivar differences in these traits will restrict the application of EVs to pasture cultivar evaluation. This gap is now being addressed by new industry initiatives.
\end{abstract}

Keywords: pasture cultivars, evaluation, traits, economic values, performance values

\section{Introduction}

The historical approach to pasture cultivar evaluation in New Zealand is to measure and report single trait values for a range of cultivars within a species. Examples of this approach include the National Forage Variety Trial (NFVT) system operated by the New Zealand Plant Breeders Research Association (NZPBRA), and the Advanced Yield Trial (AYT) system used by Agriseeds Ltd. which follows the same protocols. NFVT and AYT trials are used to compare the seasonal dry matter yield of perennial ryegrass cultivars (e.g. Easton et al. 2001; Kerr et al. 2012), annual ryegrass and hybrid ryegrass (e.g. Easton et al. 1997) at multiple sites throughout New Zealand. These trials regularly demonstrate significant differences between cultivars in DM yield. From this we can conclude that plant breeding is resulting in changes in agronomic performance, but the estimated economic impact of these changes on farm businesses is not routinely estimated.

The ultimate measure of the gains being achieved through breeding is the improvement in farm profit that can be achieved when farmers use new cultivars to renew pastures (Lee et al. 2012). This is well beyond the scope of NFVT and AYT trials, but is of direct interest to farmers. One way this gap can be bridged is through the use of economic values (EVs) for plant traits. Economic values can be placed on all important plant productivity traits such as seasonal dry matter yield, metabolisable energy and persistence. Economic values can then be combined with deviations of trait values (generally expressed as cultivar means relative to a genetic base) and summed to provide an overall economic value of those cultivars to farm businesses. In this approach, multiple traits are considered, and the trade-offs between them can be incorporated in ways that are not possible if using single trait values. The outcomes of such an analysis can include an overall, multi-trait economic ranking for different cultivars within a species.

A clear advantage of this approach is that the information provided relates to expected farm profit, which is tangible to farmers, rather than to dry matter yield or digestibility, which are not so easy for farmers to interpret. However, there are many assumptions involved in the calculation and use of EVs, and different methods for arriving at the end point. The aim of this paper is to define what is meant by the term "economic value(s)", to review methods for calculating EVs including the assumptions involved, and to propose ways in which information on EVs could be used in the evaluation of pasture plant cultivars in New Zealand.

\section{What are Economic Values?}

An economic value for a specific trait is the estimated change in operating profit of a farm system resulting from a defined step change in the expression of the trait (McEvoy et al. 2011):

\section{Economic value $=\Delta$ operating profit $/ \Delta$ trait of interest} (Eq. 1)

So, for example, if an extra $300 \mathrm{~kg} \mathrm{DM} / \mathrm{ha}$ of pasture is grown in winter ( $\Delta$ trait of interest $=300$ ), and the operating profit of the farm system improves by $\$ 90 / \mathrm{ha}$ ( $\Delta$ operating profit $=90$ ), then the $\mathrm{EV}$ of the additional winter feed is $90 / 300=\$ 0.30$ per kg extra dry matter. EVs are usually expressed as $\$$ per unit change of the trait of interest. It is important to note that the EV is not the same as the cost of growing pasture: it is an estimate 
of the economic return to the farm business of pasture traits. EVs can be calculated in different ways, but a common approach involves three main steps:

1. Calculate the physical and financial performance of a base farm system for the enterprise and region of interest. For example, this could be a sheep breeding farm in central Hawke's Bay, using typical stock policies and long-term average pasture growth rates for the region.

2. Recalculate the physical and financial performance of the system after introducing a change in the value of the trait of interest, for example a lift in pasture growth rates throughout the year, or extra pasture growth in a specific season of the year.

3. Calculate the difference in the financial performance of the "new" system compared to the "base" system, and express this as a function of the change in the trait implemented in the "new" system.

EVs for pasture traits are directly analogous to the Production Worth (PW) of dairy cattle in New Zealand. PW is calculated for dairy cattle based on seven core traits: milk protein yield, milk fat yield, milk volume, liveweight, fertility, residual survival and somatic cell score (www.nzael.org.nz). Each trait (expressed as production values) has an associated $\mathrm{EV}$, and the $\mathrm{PW}$ for a dairy cow is a weighted, economic index that reflects the combined outcomes of the trait values based on her performance and the performance of her ancestors. The concept of EVs is well entrenched in animal evaluation systems, but has not been developed in a systematic way for pasture evaluation systems. However, several studies have investigated economic values for pastures, with different objectives in mind. These studies are reviewed in the following section.

\section{The development and application of pasture EVs}

In a seminal analysis of pasture EVs, Doyle \& Elliott (1983) noted that "Grass is not a traded commodity and its value has to be imputed from its contribution to livestock production.” Doyle \& Elliott (1983) observed that the apparent value of pasture will vary depending on the season of production and the livestock activity under consideration. They recognised four economic benefits of an increase in grass production: “(i) an increase in the stocking rate; (ii) a reduction in the dependence on alternative feeds; (iii) a reduction in the need to buy in fodder (hay) or rent additional grassland; and (iv) the release of land for alternative enterprises such as cereals and potatoes." Doyle \& Elliott (1983) used typical livestock and crop gross margins, standard feed requirements for livestock production, investment costs per animal, feed costs, operational costs, and opportunity costs to investigate all four situations in the UK. They concluded that, at 1982 price levels, economic values for grass ranged between 1.4 and 10.6 pence per $\mathrm{kg} \mathrm{DM}$ depending on when the additional grass was grown and how it was used.

The first attempt to calculate economic values for different pasture cultivars was published by Brookes et al. (1993), who applied computer models to compare the economic efficiency of milk production from three perennial ryegrass cultivars with different seasonal patterns of pasture growth. For each cultivar, Brookes et al. (1993) used average monthly pasture growth rates from agronomic trials conducted over 2 years at four locations in a feed budgeting programme to find the maximum stocking rate that could be carried while maintaining the farm system within defined pre- and post-grazing pasture mass limits. All three cultivars produced similar total annual dry matter yields. However, one cultivar ('Embassy') produced $10 \%$ more dry matter during January-August, and 5\% less dry matter in September-December, than the other two cultivars ('Supernui' and 'Yatsyn I'). Brookes et al. (1993) calculated that a system based on 'Embassy' could support $4-6 \%$ more cows per hectare than the other two cultivars, with $40-50 \%$ less supplementary feed, and resulted in a 5-7\% increase in gross margin. A linear programme model was used to estimate that extra pasture grown during January-August was worth $\$ 0.23$ to $\$ 0.25$ per $\mathrm{kg} \mathrm{DM}$ whereas extra pasture grown in September-December has to be made into supplements and was worth only $\$ 0.06$ to $\$ 0.07$ per kg DM.

In southern Australia, Chapman \& Kenny (2005) and Chapman et al. (2011) used the dynamic dairy system model UDDER (Larcombe 1989) to calculate the economic value to dairy systems of extra feed consumed in each of the four seasons of the year. Their chief purpose was to lay a basis by which farmers could weigh up likely returns from adopting complementary (to perennial ryegrass) pastures or crops against the cost of growing extra feed in different seasons, recognising that each farm has different resources and therefore cost structures when it comes to growing feed. Chapman et al. (2011) modelled several different "base" farm systems, and then added $10 \%$ of the feed consumed per hectare per year in the base simulation to new simulations. Extra feed was added in each of the four seasons only, or was spread equally across the year in pro rata proportion to the base monthly growth rate. The efficiency with which additional feed could be harvested was greatest in summer in all of the new simulations. This translated into a consistent economic return of between $\$ 0.26$ and $\$ 0.34$ per $\mathrm{kg}$ extra DM in summer, compared to $\$ 0.01$ to $\$ 0.22$ in spring, and $\$ 0.11$ to $\$ 0.24$ when extra feed was available all year 
round.

In the most comprehensive analysis of its type, McEvoy et al. (2011) systematically calculated EVs for several productivity traits in Irish dairy systems as follows: $€ 0.15 / \mathrm{kg} D M$ for spring yield, $€ 0.03 / \mathrm{kg} D M$ for midseason yield, $€ 0.10 / \mathrm{kg}$ DM for autumn yield, $€ 0.008$ to $€ 0.010$ per unit change in DM digestibility per kg DM yield in May-August inclusive, and $-€ 4.96$ per $1 \%$ decrease in persisitency per ha per year. The EV for persistency was calculated as an annualised cost of renewing pasture so that pastures which needed renewing more regularly (than the 10-year assumed average) had a negative EV for persistency. McEvoy et al. (2011) then combined these EVs with observed data for DM yields and digestibility of 20 perennial ryegrass cultivars measured over 2 years to calculate an overall economic merit value for each cultivar. The range in economic merit values for the DM digestibility trait across the 20 cultivars (-€77.33 to $€ 78.07)$ was larger than the range in the midseason and autumn yield merit values, and similar to the range in spring merit values (-€72.37 to €86.18).

\section{Calculating EVs}

Computer models are essential for calculating EVs. Linear programmes (LP) and dynamic systems models can be used for the purpose. The first objective when parameterising these models must be to maximise the efficiency with which extra feed, or improved feed quality, is converted into animal product, since this is what good farmers would always aim to achieve. LP find the combination of management factors that maximise profit in response to a change in pasture traits, while keeping the system within certain boundaries set by the user (e.g., for pasture cover at critical times of the year). Several management variables can be allowed to "float" in LP, including stocking rate.

By contrast, with dynamic models, the user decides which management factors to manipulate in order to find the maximum profit while maintaining key system indicators (e.g. pasture cover, animal body condition score) within the range required to ensure the system is sustainable. A practical approach in this case is to closely reproduce the pasture cover curve and the body condition score curve of the "base" simulation when simulating a change in a pasture trait (e.g. Chapman et al. 2011).

Only a restricted number of management variables should be open to change in dynamic models, so that the result is not dependent on adjustments to a whole raft of different management parameters. A useful guide here is to restrict changes to the management decisions that farmers are most familiar with: for example, nitrogen $(\mathrm{N})$ fertiliser inputs, hay/silage conservation policy, length of the grazing rotation, and the feeding of forage supplements. These all directly impact on the efficiency of use of pasture. They are practical and realistic responses to changes in pasture growth. There are direct and/or indirect costs associated with most of them (e.g. silage has a direct cost of harvesting, storing and feeding plus an indirect cost associated with losses of dry matter and feed quality): increasing or decreasing these inputs leads directly to changes in profit and, therefore, economic values. It follows that, to implement this approach, dynamic models must give the user access to all the key management parameters, in time steps that mirror the frequency of tactical decision making on farms (days, rather than months).

The alternative approach with dynamic models is to alter strategic management factors, such as stocking rate, to utilise the extra feed. Logically, this approach will be most effective when the change in the pasture trait is large, and/or occurs consistently across the year. If the purpose is to calculate EVs for pasture evaluation, then the difference in performance between best and poorest cultivars in traits is generally quite small: for example, $10 \%$ in the case of total annual dry matter production of perennial ryegrass cultivars (Easton et al. 2001), or around $300 \mathrm{~kg} \mathrm{DM} / \mathrm{ha}$ in summer also for perennial ryegrass (www.dairynzfvi.co.nz; Kerr et al. 2012). Farmers are less likely to change stocking rate in response to differences of this magnitude, given that a change of stocking rate means a change in animal numbers, and therefore possible changes in several other aspects of the system such as labour or capital requirements. Consequently, changes in tactical management can be used to derive EVs when changes in pasture production are relatively small.

The choice of model to calculate EVs is important. There are many examples of dynamic models for most livestock industries (e.g. Bryant \& Snow 2008). Each model represents biophysical processes in a slightly or significantly different manner - some highly complex, others relatively simple. Consequently, when used to estimate EVs, they will produce slightly different outcomes. Bryant et al. (unpublished data) derived EVs for seasonal dry matter yield of perennial ryegrass for a typical Waikato dairy farm from a range of models: Farmax Dairy Pro (Bryant et al. 2010), UDDER (Larcombe 1989), and the DairyNZ Whole Farm Model (Beukes et al. 2008). Relevant monthly pasture growth rates were adjusted upwards so that the total increase in pasture production over a season (winter, early spring, late spring, summer, or autumn) was $365 \mathrm{~kg} \mathrm{DM} / \mathrm{ha}$. A further scenario was included where daily pasture growth rate increased by $1 \mathrm{~kg} \mathrm{DM} / \mathrm{ha}$ over the entire year, to simulate the same increase in total feed supply without a change in seasonality. Extra feed was utilised 


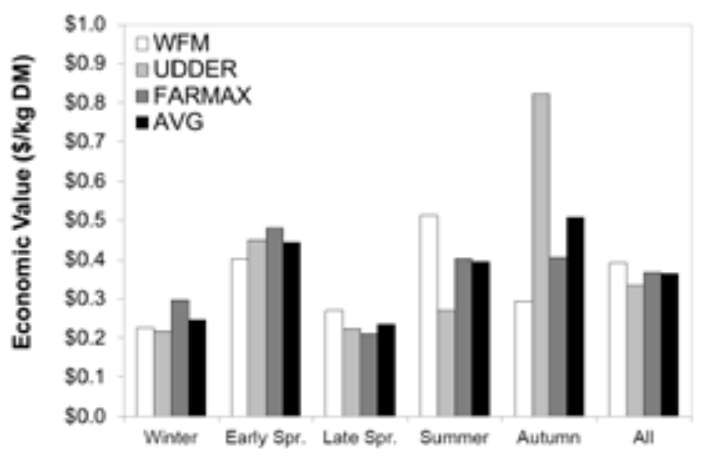

Figure 1. Economic value of extra feed within seasons, and spread evenly year-round ('All'), estimated using DairyNZ Whole Farm Model (WFM), UDDER, Farmax Dairy Pro (FMX) and the average of the three models (AVG).

by existing cow numbers by manipulating tactical use of $\mathrm{N}$ fertiliser, supplements and silage conservation decision rules.

For the Waikato spring calving system, extra feed was most valuable, on average, in autumn $(\$ 0.51 / \mathrm{kg} \mathrm{DM}$, Figure 1). Feed supplied in early spring was next most valuable $(\$ 0.44 / \mathrm{kg} \mathrm{DM})$, followed by summer $(\$ 0.39 /$ $\mathrm{kg} \mathrm{DM})$, winter $(\$ 0.25 / \mathrm{kg} \mathrm{DM})$ and late spring $(\$ 0.23 /$ $\mathrm{kg} \mathrm{DM})$. The models were relatively consistent in their estimation of EVs, with extra feed in early spring (July and August) emerging as the most important and extra feed in late spring (September and October) the least important (Figure 1). The weighted average economic values for extra feed available over the whole year (no change in seasonality) from each of the models ranged from $\$ 0.33$ to $\$ 0.39 / \mathrm{kg} \mathrm{DM}$.
Based on this comparison, Farmax Dairy Pro was used to estimate EVs for farm systems in upper North Island (e.g., Waikato), lower North Island (e.g., Manawatu), upper South Island (e.g., Canterbury), and lower South Island (e.g., Southland) applying the same general decision rules. The key physical details for these systems are shown in Table 1, and the results are presented in Table 2. There was a general trend for declining value of summer and autumn feed moving from north to south. Extra feed was most valuable in early spring and autumn in the Waikato, and in winter and early spring in Canterbury and Southland. There was very little difference in the seasonal value of feed when comparing Canterbury and Southland. These EVs are now being used in the DairyNZ Forage Value Index (DairyNZ \$FVI; www.dairynz.fvi.co.nz) system (Bryant et al. 2012; Chapman et al. 2012) which ranks perennial ryegrass cultivars according to an overall economic index which is the sum of five seasonal dry matter yield performance values multiplied by the EVs. Performance values are defined and described below.

\section{Limitations, and methodological considerations}

There are several issues associated with the calculation of EVs that must be kept in mind. These include:

1. EVs will only be as good as the models themselves, the assumptions made in using them, and the data upon which they are based. For New Zealand dairy systems, decision rules for maximising pasture grown and eaten are well known (Macdonald et al. 2010). There is also benchmarking information available to describe typical ("base") dairy systems, the range in

Table 1. Physical summary information for dairy systems simulated in Farmax DairyPro in four regions of New Zealand, for estimating the economic value of additional pasture dry matter.

Region

\begin{tabular}{lcccc} 
& $\begin{array}{c}\text { Upper North } \\
\text { Island }\end{array}$ & $\begin{array}{c}\text { Lower North } \\
\text { Island }\end{array}$ & $\begin{array}{c}\text { Upper South } \\
\text { Island }\end{array}$ & $\begin{array}{c}\text { Lower South } \\
\text { Island }\end{array}$ \\
\hline Effective milking area (ha) & 106 & 91 & 200 & 171 \\
\% milking area irrigated & 0 & 0 & 100 & 0 \\
Stocking rate at peak (cows/ha) & 3.05 & 3.05 & 3.43 & 3.28 \\
Milksolids (kg/ha) & 1,003 & 1,018 & 1,359 & 1,228 \\
Milksolids (kg/cow) & 329 & 333 & 2796 & 374 \\
Lactation length (days) & 262 & 10 & 17 & 254 \\
Supplements as \% total feed eaten & 15 & 118 & 201 & 10 \\
Nitrogen applied (kg/ha) & 140 & On & Off & 157 \\
Dry cows wintered on or off? ${ }^{1}$ & On & On
\end{tabular}

1 "On" or "off" refers to the milking platform. In Upper South Island, dry cows were fed crops on support land. In Lower South Island, dry cows were fed crops grow on the milking platform. 
management inputs used, and costs and prices (e.g., DairyNZ 2010, 2011). The data in Figure 1 suggest generally small differences in estimated EVs among the dynamic dairy system models (e.g. in winter, early spring and late spring), giving confidence that any of the models would be appropriate for this purpose. As noted earlier, there are no recent examples of EVs for New Zealand sheep or beef cattle systems. However, Farmax also handles sheep and beef systems, or spread sheet approaches could be used. Therefore, it should be possible to calculate reliable EVs for pasture traits in these industries.

2. Using dynamic models for calculating EVs does require more operator experience than using simpler models such as LP. Dynamic models deal with plant-animal interactions better than LP, which is a potential advantage when it comes to calculating EVs for pasture nutritive value traits. It is important that a well-structured set of guidelines is prepared before running multiple simulations with dynamic models so that consistent policy changes are implemented across all simulations to avoid confounding results. All simulations should be carefully documented, so that cause and effect can be established clearly.

3. The magnitude of the change in trait values that is modelled should be consistent with the expected change in the management practice being investigated, for example incorporating new cultivars into pastures, or including forage crops in the system. If larger changes in pasture trait expression are simulated, the assumptions or decision rules need to change. A substantial change in total feed available may require strategic management changes, such as increasing stocking rate, to simulate the effect appropriately.

4. EVs used for genetic evaluation are regionspecific, not farm-specific. Farms differ in their management structure, and this can lead to different EVs for feed grown (e.g., the comparison of "average" and "top 10\%" farms described by Chapman et al. 2011). Hence EVs should be treated as a general guide only, rather than an accurate prediction for individual farms. Potentially, individual farms could be simulated in the Farmax model or a similar tool and farmspecific EVs calculated, provided the necessary information on physical farm inputs, production, and cost structure is available. A service such as this could be embedded within farm financial analysis or benchmarking programme, if there was sufficient demand for the information.

5. Because costs and prices change regularly, financial assumptions must be updated regularly (generally annually) to accurately calculate EVs.

\section{Performance values and economic indices}

Performance values (PVs) are distinct from EVs. PVs relate to specific traits and belong to cultivars, whereas EVs relate to the farm system in which cultivars may be used. In New Zealand, the best sources of data for calculating PVs are NFVT or AYT dry matter yield comparisons. These trials typically include 10-15 perennial ryegrass cultivars, are repeated at several sites throughout New Zealand, and are sampled for pre-grazing/cutting dry matter yield for 3 years. PVs for seasonal dry matter yield for individual cultivars are calculated relative to a genetic base of cultivars. In the DairyNZ FVI system, the genetic base is taken to be a group of perennial ryegrass cultivars first included in the NFVT system before 1996. PVs are estimated for two zones: upper North Island, and the rest of New Zealand. The selection of these two zones was based on genotype $\times$ region analyses that revealed significant differences in cultivar rankings in the upper North Island compared to sites elsewhere in New Zealand.

When PVs are spliced with EVs for the region of interest, an integrated economic index can be calculated

Table 2. Economic values ( $\$ / \mathrm{kg}$ additional dry matter) for seasonal dry matter yields in dairy systems in four regions of New Zealand

Region

\begin{tabular}{lcccc}
\hline Season & Upper North Island & Lower North Island & Upper South Island & Lower South Island \\
\hline Winter & 0.30 & 0.37 & 0.45 & 0.40 \\
Early spring & 0.48 & 0.47 & 0.42 & 0.46 \\
Late spring & 0.21 & 0.17 & 0.29 & 0.23 \\
Summer & 0.40 & 0.33 & 0.17 & 0.12 \\
Autumn & 0.41 & 0.32 & 0.29 & 0.27 \\
\hline
\end{tabular}

* Winter = May and June (North Island) and June and July (South Island), Early Spring = July and August (North Island) and August and September (South Island), Late Spring = September and October (North Island) and October and November (South Island), Summer = November to January (North Island) and December to January (South Island) and Autumn = February to April (North Island) and March to May (South Island). 
for each cultivar, and cultivars can be ranked from highest to lowest index value. This is the method used by McEvoy et al. (2011) for Irish dairy pastures, and for the DairyNZ \$FVI system (Bryant et al. 2012; Chapman et al. 2012).

In New Zealand, the development of multi-trait economic indices for pasture cultivars is currently limited by the absence of:

- sufficient trial data for several of the major commercial perennial ryegrass cultivars. For a cultivar to be eligible for an index value, data must be available from a minimum number of trials conducted according to accepted trial protocols;

- data on specific perennial ryegrass by endophyte combinations. Until relatively recently, cultivars were generally tested with standard endophyte (SE) only. There are host genotype by endophyte interactions (Popay et al. 2003), which means that the PV for, e.g. cultivar $X$ with AR37 cannot be assumed to be the same as the PV for cultivar $Y$ with AR37. Additionally, SE may depress milk production per cow through alkaloid effects especially in the warmer, drier climates of northern New Zealand (Bluett et al. 2005): the FVI may need to take this into account as well, although we note that very few cultivars are still marketed with SE in the northern North Island;

- systematic data on the persistence and nutritive value of perennial ryegrass cultivars; and

- data on yield, persistence and nutritive value of cultivars within other species, such as tall fescue, lucerne and white clover.

Many of these limitations are currently being addressed in revised trial protocols and an expanded trial base, for example in the NFVT system. It will be several years before data from the revamped systems becomes available. In the meantime, information in existing trial databases is being used to develop economic indices to support farmer cultivar choices for pasture renewal, albeit based only on the seasonal dry matter yield trait at this stage.

\section{Conclusions}

Dynamic farm system models and linear programmes are suitable tools for calculating the economic value of specific pasture traits in different livestock industries. While EVs have so far only been applied to perennial ryegrass production traits (mostly dry matter yield), mostly in dairy systems, there is no reason why they cannot also be applied to other species including forage crops and, when better information is available, to environmental traits such as the potential to reduce $\mathrm{N}$ loss or greenhouse gas emissions. EVs can be used in a number of ways: to support farmer decisions regarding the benefits and costs of options for supplying additional feed at different times of the year; to compare the likely economic payoff from pursuing various plant breeding objectives; and, in combination with performance values, to calculate multi-trait economic indices for pasture cultivars. For the latter purpose, more data are required on cultivar traits, especially nutritive value and persistence, to allow calculation of performance values. Better evaluation systems should help increase farmer confidence in pasture renewal, support better cultivar selection decisions, improve the rate of genetic gain in pasture performance, and lift farm business profitability.

\section{ACKNOWLEDGEMENTS}

Pierre Beukes for assistance in the calculation of economic values using the DairyNZ Whole Farm Model. Graham Kerr, Glen Judson, Tim Cookson, and Grant Edwards for helpful discussion regarding the application of economic values to pasture evaluation.

\section{REFERENCES}

Beukes, P.C.; Palliser, C.C.; MacDonald, K.A.; Lancaster, J.A.S.; Levy, G.; Thorrold, B.S.; Wastney, M.E. 2008. Evaluation of a whole-farm model for pasture-based dairy systems. Journal of Dairy Science 91: 2353-2360.

Bluett, S.J.; Thom, E.R.; Clark, D.A; Macdonald, K.A.; Minneé, E.M.K. 2005. Effects of perennial ryegrass infected with either AR1 or wild type endophyte on dairy production in the Waikato. New Zealand Journal of Agricultural Research 48: 197-212.

Brookes, I.M.; McRae, A.F.; Gray, D.I.; Cameron, N. 1993. Economics of milk production from ryegrass cultivars with different seasonal growth patterns. Proceedings of the 17th International Grassland Congress: 1294-1295

Bryant, J.R.; Snow, V.O. 2008. Modelling pastoral agro-ecosystems: a review. New Zealand Journal of Agricultural Research 51: 349-363.

Bryant, J.R.; Ogle, G.; Marshall, P.R.; Glassey, C.B.; Lancaster, J.A.S.; García, S.C.; Holmes, C.W. 2010. Description and evaluation of the Farmax Dairy Pro decision support model. New Zealand Journal of Agricultural Research 53: 13-28

Bryant, J.; Chapman, D.; McMillan, W.; Thorrold, B.; Willocks, M.; Green, D.; Kerr, G.; Judson, G.; Cookson, T.; Edwards, G. 2012. Valuing the forage you grow: Economic indices for pasture cultivars. Proceedings of the South Island Dairy Event: pp. 2834.

Chapman, D.F.; Kenny, S. 2005. Alternative feedbase systems for southern Australia dairy farms. 3 . Economic returns from extra dry matter consumption. Proceedings of the 20th International Grassland Congress: 463. 
Chapman, D.F.; Kenny, S.N.; Lane, N.L. 2011. Pasture and forage crop systems for non-irrigated dairy farms in southern Australia. 3. Estimated economic value of additional home-grown feed. Agricultural Systems 104: 589-599.

Chapman, D.; Bryant, J.; McMillan, W.; Thorrold, B.; Willocks, M.; Green, D.; Kerr, G.; Judson, G.; Cookson, T.; Edwards, G. 2012. An economic forage value index for New Zealand dairy farmers. Proceedings of the 5th Australasian Dairy Science Symposium: (in press).

DairyNZ 2010. New Zealand Dairy Statistics 2009-10. DairyNZ and LIC, Hamilton. 52 pp.

DairyNZ 2011. DairyNZ Economic Survey 2009-10. DairyNZ, Hamilton. 60 pp.

Doyle, C.J.; Elliott, J.G. 1983. Putting an economic value on increases in grass production. Grass and Forage Science 38: 169-177.

Easton, S.; Baird, D.; Baxter, G.; Cameron. N.; Hainsworth, R.; Johnston, C.; Kerr, G.; Lyons, T.; McCabe, R.; Nichol, W.; Norriss, M.; Stewart, A.; Thom, E. 1997. Annual and hybrid cultivars in New Zealand. Proceedings of the New Zealand Grassland Association 59: 239-244.

Easton, H.S.; Baird, D.B.; Cameron, N.E.; Kerr, G.A.; Norriss, M.; Stewart, A.V. 2001. Perennial ryegrass cultivars: herbage yield in multi-site plot trials. Proceedings of the New Zealand Grassland Association 63: 183-188.
Kerr, G.A.; Chapman, D.F.; Thom, E.R.; Matthew, C.; Van der Linden, A.; Baird, D.B.; Johnston, E.; Corkran, J.R. 2012. Evaluating perennial ryegrass cultivars: improving accuracy. Proceedings of the New Zealand Grassland Association 74: 127-136.

Larcombe, M.T. 1989. The effects of manipulating reproduction on the productivity and profitability of dairy herds which graze pasture. PhD Thesis. University of Melbourne.

Lee, J.M.; Matthew, C.; Thom, E.R.; Chapman, D.F. 2012. Perennial ryegrass breeding in New Zealand: a dairy industry perspective. Crop and Pasture Science 63: 107-127.

Macdonald, K.A.; Glassey, C.B.; Rawnsley, R.P. 2010. The emergence, development and effectiveness of decision rules for pasture based dairy systems. Proceedings of the 4th Australasian Dairy Science Symposium: 199-209. ISBN 978-0-86476-230-6

McEvoy, M.; O’Donovan, M.; Shalloo, L. 2011. Development and application of an economic ranking index for perennial ryegrass cultivars. Journal of Dairy Science 94: 1627-1639.

Popay,A.J.; Hume, D.E.; Davis, K.L.; Tapper, B.A. 2003. Interactions between endophyte (Neophytodium spp.) and ploidy in hybrid and perennial ryegrass cultivars and their effects on Argentine stem weevil (Listronous bonariensis). New Zealand Journal of Agricultural Research 46: 311-319. 
